\title{
Regioselectivity Control of the Ring Opening of Epoxides With Sodium Azide in a Microreactor
}

\author{
Rajesh Munirathinam, Daejune Joe, Jurriaan Huskens and Willem Verboom* \\ Laboratory of Molecular Nanofabrication, MESA+Institute for Nanotechnology, University of Twente \\ P.O. Box 217, 7500 AE Enschede, The Netherlands
}

\begin{abstract}
The reaction of different types of aromatic and aliphatic epoxides with sodium azide to give vicinal azido alcohols was studied in a microreactor with and without pillars in the channels. Dependent on the substrate, the regioselectivity of the ring opening is affected by the used solvent system, viz. acetonitrile-water (sometimes with $10 \%$ acetic acid to promote the reactivity of substrates) or $t$-butyl acetate-water containing Tween 80 as a surfactant. For styrene oxide and $\alpha$-methylstyrene oxide, the $\alpha / \beta$ regioselectivity changes from 4 to 10 and 1.7 to 6.2 , respectively, going from acetonitrile-water to Tween80-containing $t$-butyl acetate-water. The addition of a surfactant (Tween80) stabilizes the interface in the biphasic $t$-butyl acetate-water. Pillar-containing microreactors gave better conversions than microreactors without pillars and lab scale reactions, probably due to better mixing.
\end{abstract}

Keywords: microreactors, epoxides, regioselectivity, 1,2-azido alcohols, surfactants

\section{Introduction}

Vicinal azido alcohols are versatile compouds in organic synthesis [1] because they not only constitute as components of biologically active natural products but also serve as important precursors in the synthesis of amino sugars [2], carboxylic nucleosides [3], lactams [4], oxazolines [5], and amino alcohols [6]. The method most employed to prepare 1,2-azido alcohols is azidolysis of the corresponding epoxides (Scheme 1) [7]. It uses aqueous solutions of sodium azide $\left(\mathrm{NaN}_{3}\right)$ and ammonium chloride $\left(\mathrm{NH}_{4} \mathrm{Cl}\right)$ or organic media with trimethylsilyl azide as the azide source. However, it generally requires long reaction times (12-48 h), and the formation of an azidohydrin is often accompanied by diol formation, toxic $\mathrm{HN}_{3}$ formation in strong acidic medium, and lack of regioselectivity. To overcome some of these hurdles, a number of improved methodologies have been developed for the azidolysis of epoxides using Lewis acids [8], controlling the $\mathrm{pH}$ of the reaction medium ( $\mathrm{pH} 4.2$ and 9.5 give rise to a different regioselectivity) [9], phase transfer catalysts [10], and transition and lanthanoid metal catalysts [11].

Though the above mentioned methods have their own advantages, many of these procedures suffer from one or more of the limitations such as longer reaction times, strongly acidic conditions, unsatisfactory yields, expensive catalysts, and lack of regioselectivity. Therefore, there is a need and challenge to develop alternative mild and effective methods for the synthesis of 1,2-azido alcohols.

The ring opening of epoxides with azides follows an $\mathrm{S}_{\mathrm{N}} 2$ mechanism under neutral or basic conditions [12]. Generally, when there are no electronic effects induced by the substituents, the azide ion prefers to attack the less substituted carbon atom of the epoxide. However, in the presence of an aromatic ring as the substituent, electronic effects operate to direct the incoming azide group more to the benzylic position because the positive charge at the benzylic carbon is stabilized by resonance with the aromatic ring. Under acidic conditions, the oxygen of the epoxide is protonated [9], developing more positive charge on the epoxide carbon bearing more substituents, to which azide attack is enhanced. In general, the presence of a Lewis acid has the same effect enhancing the reaction.

Microreactors are evolving as a promising tool to perform organic reactions [13] [14] [15]. It provides numerous advantages

\footnotetext{
* Author for correspondence: w.verboom@utwente.n
}

Scheme 1. Ring opening reaction of epoxides with azide

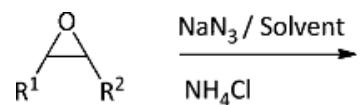

$\mathbf{R}^{1}=$ aliphatic, aromatic, alkenyl

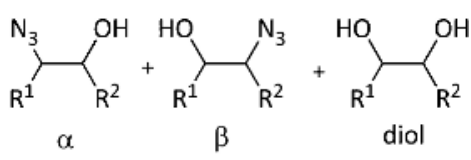

$\mathbf{R}^{2}=$ aliphatic, $\mathrm{H}$

like, very large surface area-to-volume ratio, rapid heat and mass transfer, which in turn influence the reaction time and yield. The small dimensions of the microchannels result in a short radial diffusion time with better mixing than in the conventional system [16]. In addition, it is very safe to carry out reactions with toxic substances [17], and for multiphase reactions, the interfacial interaction can be controlled using different flow regimes.

Using a microreactor as a useful reaction platform, in the present work, we performed the ring opening reaction of epoxides using $\mathrm{NaN}_{3}$ as an inexpensive azide source to form 1,2azido alcohols, in a continuous flow glass microreactor with and without pillars under different conditions (homogeneous solvent mixture, biphasic solvent mixture with a surfactant, presence of acid, and varying temperature) to study the effect on the reaction time, the regioselectivity $(\alpha / \beta)$, and the formation of side product (diol).

\section{Results and Discussion}

Using styrene oxide as a model substrate (Scheme 2), optimization reactions were carried out to investigate the influence of the solvent system, a surfactant, Lewis acids, temperature, and the presence/absence of pillars in the microreactor. The classical protocol [18] for the ring opening of epoxides by azides described by Caron and Sharpless uses $\mathrm{MeOH} / \mathrm{H}_{2} \mathrm{O}$ (8:1) as solvent medium, 5 equiv. of $\mathrm{NaN}_{3}$, and 2.2 equiv. of $\mathrm{NH}_{4} \mathrm{Cl}$, resulting in a heterogeneous reaction mixture. However,

Scheme 2. Ring opening of styrene oxide with sodium azide

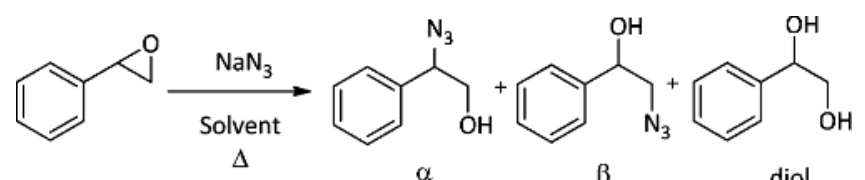
diol 


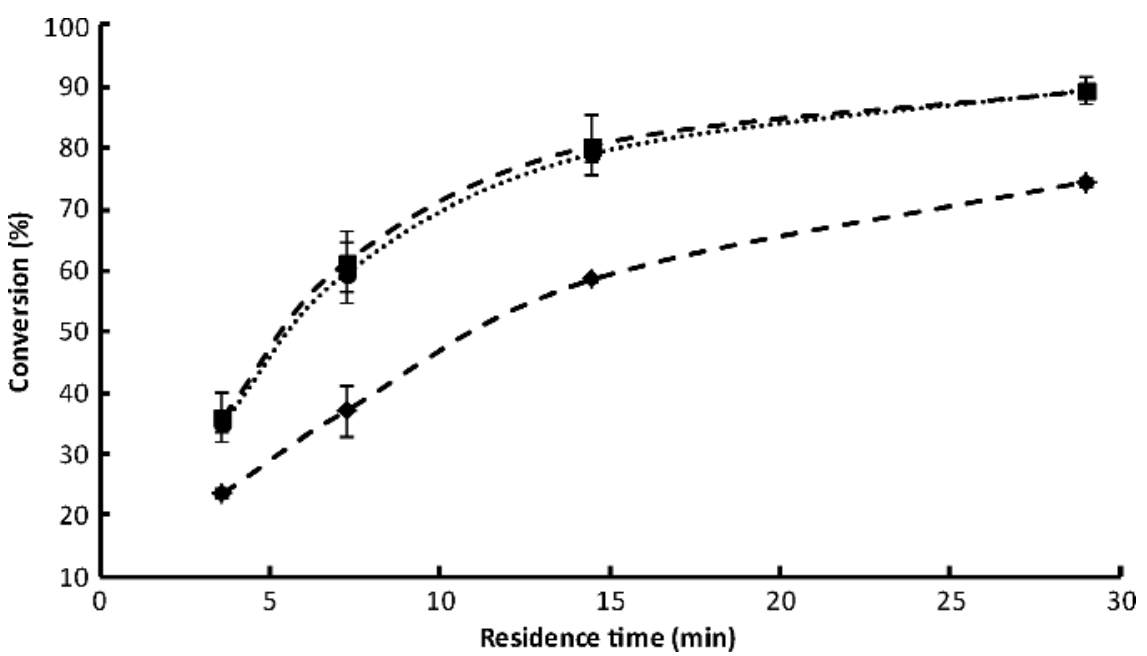

Figure 1. Ring opening of styrene oxide by $\mathrm{NaN}_{3}$ using 1:1 $\mathrm{ACN}-\mathrm{H}_{2} \mathrm{O}$. Reaction conditions: Syringe $1: \mathrm{A}=\mathrm{NaN}_{3}, \mathrm{~B}=\mathrm{NH}_{4} \mathrm{Cl}$ in water. Syringe 2: styrene oxide (C) in ACN. Flow rates of aqueous and organic phases are equal. The lines in the figure corresponds to (-- --) $2.5 \mathrm{M}(\mathrm{A}), 1.1 \mathrm{M}(\mathrm{B})$, and $0.5 \mathrm{M}(\mathrm{C}) ;(\cdots \cdots) 1.25 \mathrm{M}(\mathrm{A}), 1.1 \mathrm{M}(\mathrm{B})$, and $0.5 \mathrm{M}(\mathrm{C}) ;(----) 0.625 \mathrm{M}(\mathrm{A}), 0.55 \mathrm{M}(\mathrm{B})$, and $0.5 \mathrm{M}(\mathrm{C})$

in microreactors, in order to avoid clogging of the microchannels, a homogeneous reaction mixture is preferred.

2.1. Acetonitrile-Water Solvent Medium. A microreactor with pillars in the microchannels to induce very effective mixing was used to carry out the ring opening reaction of styrene oxide using sodium azide. Among different alcohol-water and acetonitrile-water $\left(\mathrm{ACN}-\mathrm{H}_{2} \mathrm{O}\right)$ solvent mixtures, the latter gave a homogeneous reaction mixture. Using 1:1 $\mathrm{ACN}-\mathrm{H}_{2} \mathrm{O}$, the ring opening of styrene oxide gave conversions close to $90 \%$ and a regioselectivity $(\alpha / \beta)$ of around 4 in $29 \mathrm{~min}$. Figure 1 shows that using $0.625 \mathrm{M} \mathrm{NaN}_{3}$ and $0.55 \mathrm{M} \mathrm{NH}_{4} \mathrm{Cl}$, conversions close to $75 \%(\alpha / \beta=4)$ were obtained for a reaction time of $29 \mathrm{~min}$ at $75{ }^{\circ} \mathrm{C}$. Doubling the concentration of $\mathrm{NaN}_{3}$ from $0.625 \mathrm{M}$ to $1.25 \mathrm{M}$ enhances the conversion $(89 \%)$, but the regioselectivity $(\alpha / \beta=4)$ remains the same. Increasing the concentration of $\mathrm{NaN}_{3}$ from $1.25 \mathrm{M}$ to $2.5 \mathrm{M}$, and the concentration of $\mathrm{NH}_{4} \mathrm{Cl}$ from $0.55 \mathrm{M}$ to $1.1 \mathrm{M}$, does not influence the conversion. However, there is a marginal increase in the regioselectivity, which is ascribed to the change in $\mathrm{NH}_{4} \mathrm{Cl}$ concentration from $0.55 \mathrm{M}$ to $1.1 \mathrm{M}$. $\mathrm{NH}_{4} \mathrm{Cl}$ coordinates to the epoxide [19] and thereby favors the regioselective attack at the $\alpha$-position of the styrene oxide. At high salt concentrations (2.5 $\mathrm{M} \mathrm{NaN}_{3}$ and $0.55 \mathrm{M} \mathrm{NH}_{4} \mathrm{Cl}$ ) over a period of $5 \mathrm{~h}$, the salts deposit on the walls of the channels, clogging the microreactor.

Furthermore, upon addition of acetic acid $(10 \%)$ to the water phase of $1: 1 \mathrm{ACN}-\mathrm{H}_{2} \mathrm{O}$, the regioselectivity $(\alpha / \beta)$ increased to 6 with nearly the same conversions $(86 \%)$. The increased regioselectivity is attributed to protonation of the epoxide, favoring the azide to preferentially attack the $\alpha$-carbon of the styrene oxide. So far, the flow rates of aqueous and organic phases are equal. Applying differential flow rates of the aqueous and organic phases of $\mathrm{ACN}-\mathrm{H}_{2} \mathrm{O}$ showed that higher flow rates of aqueous to organic phase $(5: 1)$ resulted in a higher regioselectivity $(\alpha / \beta=7)$ and fast conversions $(94 \%)$ in around 4 min of residence time, compared to equal flow rates. The increase in the conversions may be ascribed to the availability of the huge excess (12.5 equivalents) of azide. The reason for the increase in the regioselectivity may be attributed to the change in the polarity of the reaction mixture. The conversions and regioselectivity gradually decrease upon decreasing the ratio of the flow rates of aqueous and organic phases.

2.2. Influence of Process Conditions in the $\mathrm{ACN}-\mathrm{H}_{2} \mathrm{O}$ System. In order to demonstrate the efficiency of the use of a microreactor over lab scale, the ring opening reaction of styrene oxide was carried out both in a microreactor and at lab scale in
ACN $-\mathrm{H}_{2} \mathrm{O}$ under identical conditions (Figure S1, supporting information). The conversions in a microreactor $(89 \%)$ are slightly better than those at lab scale $(78 \%)$ in $\mathrm{ACN}-\mathrm{H}_{2} \mathrm{O}$, owing to the homogeneous reaction mixture present at $75{ }^{\circ} \mathrm{C}$, while the regioselectivity remained the same [20].

The temperature influence was investigated using $\mathrm{ACN}-\mathrm{H}_{2} \mathrm{O}$ (Figure S2, supporting information). Upon slowly decreasing the temperature from $75{ }^{\circ} \mathrm{C}$ to $40{ }^{\circ} \mathrm{C}$, for a residence time of $29 \mathrm{~min}$, the conversions gradually decreased from $89 \%$ to $21 \%$, while the regioselectivity $(\alpha / \beta)$ steadily increased from 4 to 8.5 .

Compared to a microreactor without pillars, the presence of pillars in a microreactor gave rise to higher conversions for ACN- $\mathrm{H}_{2} \mathrm{O}$ (increase from $76 \%$ to $89 \%$ for 29 -min residence time) under identical conditions (Figure S3, supporting information). Fluorescence images of the reaction mixture were taken using anthracene dye $(5 \mu \mathrm{M})$ in the organic phase, to monitor the interaction of aqueous and organic phases in a microreactor with and without pillars (Figure 2). In case of a microreactor with pillars using $\mathrm{ACN}$-water, a small slug is formed from time to time (Figure 2a). A microreactor without pillars using $\mathrm{ACN}-\mathrm{H}_{2} \mathrm{O}$ displays slug formation in the beginning of the channels. The slugs gradually decrease in size resulting in a homogeneous phase (Figure 2b). Because of the better mixing and a homogeneous reaction mixture obtained in a microreactor with pillars, it gives higher conversions than in one without pillars using $\mathrm{ACN}-\mathrm{H}_{2} \mathrm{O}$.

2.3. $t$-Butyl Acetate-Water Solvent Medium. Using immiscible solvents as aqueous and organic phases in flow conditions mostly results in a segmented (slug) flow. Upon formation of slugs, an internal fluid vortex is generated, resulting in rapid mixing within a slug by continuously refreshing the diffusion interface [21]. In order to study the influence of these conditions
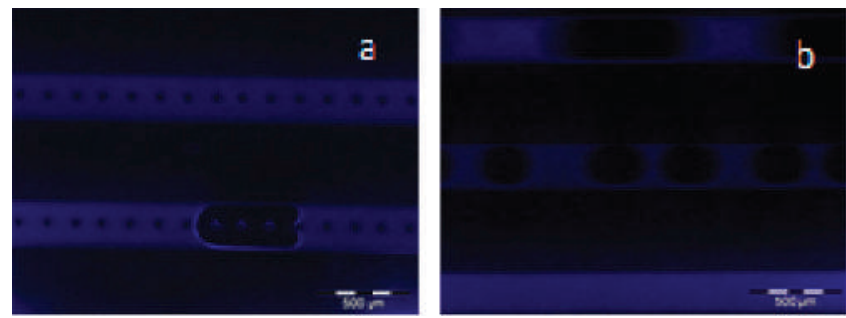

Figure 2. Fluorescence images of $\mathrm{ACN}-\mathrm{H}_{2} \mathrm{O}$ in microreactors with and without pillars. a) $\mathrm{ACN}-\mathrm{H}_{2} \mathrm{O}$ with pillars, b) $\mathrm{ACN}-\mathrm{H}_{2} \mathrm{O}$ without pillars. Flow rates of aqueous and organic phases are equal 


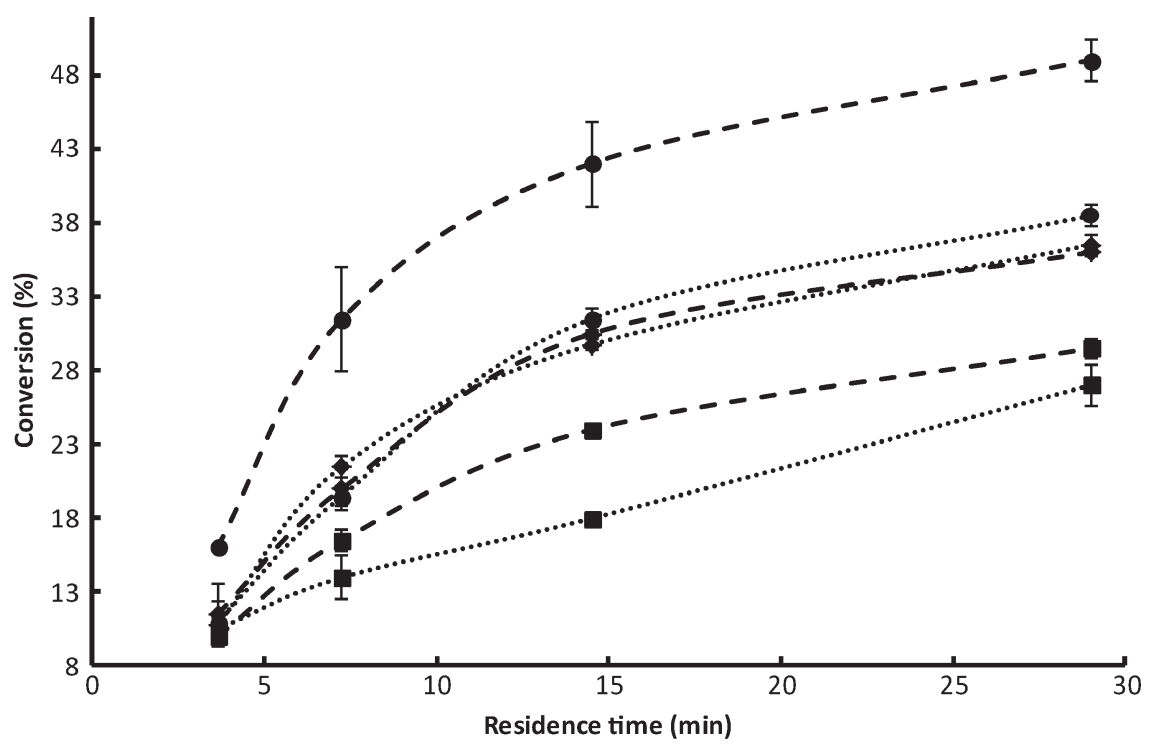

Figure 3. Ring opening of styrene oxide by $\mathrm{NaN}_{3}$ using 1:1 $t$ - BuOAc- $\mathrm{H}_{2} \mathrm{O}$. Reaction conditions: Syringe 1: $1.25 \mathrm{M} \mathrm{NaN}_{3}, 0.55 \mathrm{M} \mathrm{NH}_{4} \mathrm{Cl}$, Tween 80 $(\mathrm{v} / \mathrm{v})$ in water. Syringe 2: $0.5 \mathrm{M}$ styrene oxide in $t$-BuOAc. Flow rates of aqueous and organic phases are equal. The lines in the figure correspond to varying amounts of Tween80 in water ( $\cdots \cdots)-$ nil, $(----)-12 \mu \mathrm{L} / \mathrm{mL},(--\downarrow--)-60 \mu \mathrm{L} / \mathrm{mL},(--\bullet--)-100 \mu \mathrm{L} / \mathrm{mL},(\cdots \cdots)-150 \mu \mathrm{L} / \mathrm{mL}$, and $(\cdots \cdot \cdots)-200 \mu \mathrm{L} / \mathrm{mL}$

on the regioselectivity and the conversion, $t$-butyl acetate-water $\left(t-\mathrm{BuOAc}-\mathrm{H}_{2} \mathrm{O}\right)$ was used as the reaction medium. Although the conversions $(27 \%$ in $29 \mathrm{~min})$ are poor, the regioselectivity $(\alpha / \beta)$ has increased from 4 to 9.5 , which is more than a two-fold rise in regioselectivity compared to $\mathrm{ACN}-\mathrm{H}_{2} \mathrm{O}$ (Figure 3 ).

In order to enhance the interfacial interaction between the two phases, the influence of surfactants was studied. Using ionic surfactants like dodecyltrimethylammonium bromide (DTAB) and sodium dodecyl sulfate (SDS) in the aqueous phase containing $\mathrm{NaN}_{3}$ and $\mathrm{NH}_{4} \mathrm{Cl}$ resulted in the formation of a precipitate. However, Tween 80 as a neutral surfactant in $t$-BuOAc- $\mathrm{H}_{2} \mathrm{O}$ gave rise to a higher conversion with good regioselectivity. Upon varying the Tween 80 concentration from 12 to $200 \mu \mathrm{L} / \mathrm{mL}$ of aqueous phase, the conversions increased until the concentration of Tween 80 reached $100 \mu \mathrm{L} / \mathrm{mL}$ beyond which it declined. The regioselectivity $(\alpha / \beta)$ showed slight variations (from 11 to 9 ) upon increasing the surfactant concentration from 12 to $200 \mu \mathrm{L} / \mathrm{mL}$ of Tween 80 (Figure 3). The small changes in the regioselectivity may be ascribed to a small change in the polarity at the interface of aqueous and organic phases [22]. Fluorescence images of the reaction mixture were taken using anthracene dye $(5 \mu \mathrm{M})$ in the organic phase in order to monitor the interaction of aqueous and organic phases (Figure 4). A fine dispersion (a sort of microemulsion) of aqueous and organic phases was observed at $100 \mu \mathrm{L} / \mathrm{mL}$ of Tween 80 , resulting in a maximum conversion of $49 \%$ and a regioselectivity $(\alpha / \beta)$ of 10 (Figure $4 \mathrm{~b}$ ). However, using Tween80, 12 (Figure 4a), 60, 150, and 200 (Figure 4c) $\mu \mathrm{L} / \mathrm{mL}$ of aqueous phase showed the formation of aqueous and organic phase slugs of different sizes.
2.4. Influence of Process Conditions in the $t-\mathrm{BuOAc}-\mathrm{H}_{2} \mathrm{O}$ System. The ring opening reaction of styrene oxide was carried out both in a microreactor and at lab scale in $t$-BuOAc- $\mathrm{H}_{2} \mathrm{O}$ under identical conditions (Figure $\mathrm{S} 1$, supporting information). The conversions in a microreactor are better than those at lab scale in $t$ - BuOAc- $\mathrm{H}_{2} \mathrm{O}$, while the regioselectivity remained the same. However, the conversions at lab scale depend on the stirring speed, with good conversions at higher rates on account of the better mixing of aqueous and organic phase. However, the conversions obtained in a microreactor (49\%) are still better than at lab scale $(40 \%)$ demonstrating the efficient mixing in a microreactor with pillars [23].

Compared to a microreactor without pillars, the presence of pillars in a microreactor gave rise to higher conversions for $t$-BuOAc- $\mathrm{H}_{2} \mathrm{O}$ with Tween 80 (increase from $20 \%$ to $49 \%$ for 29-min residence time), and the regioselectivity remained the same (Figure S3, supporting information). Using $t$-BuOAc$\mathrm{H}_{2} \mathrm{O}$ having $100 \mu \mathrm{L} / \mathrm{ml}$ of Tween 80 in the aqueous phase, a microreactor with pillars shows a fine dispersion as mentioned before. However, under the same conditions in a microreactor without pillars bilayer formation is observed in the beginning of the channels. The bilayers gradually transform into slugs and continue as slugs throughout the channels (Figure 4d). The interfacial interaction between the two immiscible phases of $t$-BuOAc$\mathrm{H}_{2} \mathrm{O}$ having Tween 80 in the aqueous phase is considerably enhanced by the presence of pillars, which eventually results in higher conversions than using a microreactor without pillars.

2.5. Substrate Scope. The optimized reaction conditions for styrene oxide as the model substrate, namely $0.5 \mathrm{M}$ substrate in
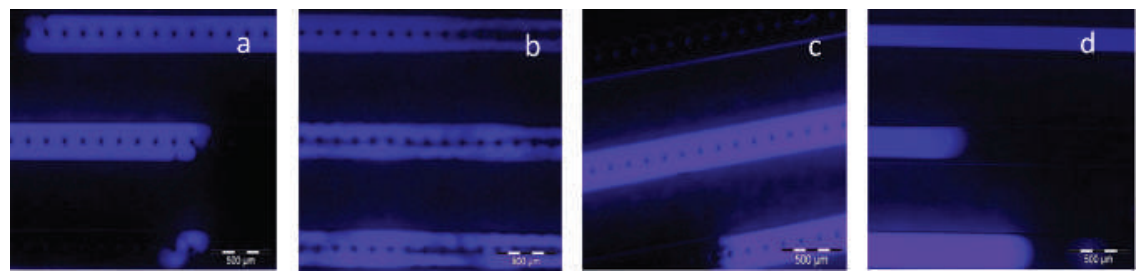

Figure 4. Fluorescence images of $t$ - BuOAc- $\mathrm{H}_{2} \mathrm{O}$ with Tween 80 in the aqueous phase: a) $12 \mu \mathrm{L} / \mathrm{mL}$, b) $100 \mu \mathrm{L} / \mathrm{mL}$, c) $200 \mu \mathrm{L} / \mathrm{mL}$ with pillars in a microreactor, d) $100 \mu \mathrm{L} / \mathrm{mL}$ without pillars in a microreactor. Flow rates of aqueous and organic phases are equal. $5 \mu \mathrm{M}$ anthracene was added to the organic phase 
Table 1. Ring opening of styrene oxide derivatives by $\mathrm{NaN}_{3}$ under different conditions

\begin{tabular}{|c|c|c|c|c|c|c|}
\hline Entry & Epoxide $^{a}$ & Solvent system & Conversion $(\%)$ & Azido-alcohol (\%) & Diol (\%) & Regioselectivity \\
\hline \multirow[b]{2}{*}{$1[1]$} & & $\mathrm{ACN}-\mathrm{H}_{2} \mathrm{O}^{b}$ & 89 & 89 & - & $4(\alpha / \beta)$ \\
\hline & & $\mathrm{ACN}-\mathrm{H}_{2} \mathrm{O}^{d}(10 \% \mathrm{AcOH}$ in water $)$ & 86 & 86 & - & $6(\alpha / \beta)$ \\
\hline \multirow{3}{*}{$2[24]$} & & $\mathrm{ACN}-\mathrm{H}_{2} \mathrm{O}^{b}$ & 96 & 93 & 3 & $\beta$ Isomer traces \\
\hline & & $\mathrm{ACN}-\mathrm{H}_{2} \mathrm{O}^{d}(10 \% \mathrm{AcOH}$ in water $)$ & $95^{e}$ & 43 & 41 & $12(\alpha / \beta)$ \\
\hline & & $t-\mathrm{BuOAc}-\mathrm{H}_{2} \mathrm{O}^{c}$ & 43 & 43 & - & $\beta$ Isomer traces \\
\hline \multirow{3}{*}{$3[25]$} & & $\mathrm{ACN}-\mathrm{H}_{2} \mathrm{O}^{b}$ & 70 & 61 & 9 & $1.7(\alpha / \beta)$ \\
\hline & & $\mathrm{ACN}-\mathrm{H}_{2} \mathrm{O}^{d}(10 \% \mathrm{AcOH}$ in water $)$ & 93 & 43 & 50 & $\beta$ Isomer traces \\
\hline & & $t-\mathrm{BuOAc}-\mathrm{H}_{2} \mathrm{O}^{c}$ & 17 & 16 & - & $6.5(\alpha / \beta)$ \\
\hline \multirow{3}{*}{$4[26]$} & & $\mathrm{ACN}-\mathrm{H}_{2} \mathrm{O}^{b}$ & 41 & 41 & - & $\beta$ Isomer traces \\
\hline & & $\mathrm{ACN}-\mathrm{H}_{2} \mathrm{O}^{d}(10 \% \mathrm{AcOH}$ in water $)$ & 41 & 38 & 3 & $\beta$ Isomer traces \\
\hline & & $t-\mathrm{BuOAc}-\mathrm{H}_{2} \mathrm{O}^{c}$ & 12 & 12 & - & $\beta$ Isomer traces \\
\hline
\end{tabular}

${ }^{a}$ Reaction conditions: Syringe $1:{ }^{b} \mathrm{NaN}_{3}(1.25 \mathrm{M})$ and $\mathrm{NH}_{4} \mathrm{Cl}(0.55 \mathrm{M})$ in $\mathrm{H}_{2} \mathrm{O} ;{ }^{c} \mathrm{NaN}_{3}(1.25 \mathrm{M}), \mathrm{NH}_{4} \mathrm{Cl}(0.55 \mathrm{M})$ and Tween $80(100 \mu \mathrm{L} / \mathrm{mL})$ in $\mathrm{H}_{2} \mathrm{O}$; ${ }^{d} \mathrm{NaN}_{3}(1.25 \mathrm{M}), \mathrm{NH}_{4} \mathrm{Cl}(0.55 \mathrm{M})$ and $10 \%$ acetic acid in $\mathrm{H}_{2} \mathrm{O}$. Syringe $2:{ }^{b, c, d}$ Substrate $(0.5 \mathrm{M})$ in the respective solvent. ${ }^{e}$ Residence time is around 4 min. Reactions were carried out in a microreactor with pillars. Residence time: 29 min. Flow rates of aqueous and organic phases are equal. Traces mean that the formation is $<2 \%$.

the organic phase and $1.25 \mathrm{M} \mathrm{NaN}_{3}$ and $0.55 \mathrm{M} \mathrm{NH}_{4} \mathrm{Cl}$ in $\mathrm{H}_{2} \mathrm{O}$ for all solvent systems, while in the case of $t-\mathrm{BuOAc}-\mathrm{H}_{2} \mathrm{O}$ also $100 \mu \mathrm{L} / \mathrm{mL}$ Tween 80 in water was present, were used to study the substrate scope starting with related compounds (Table 1). Tetrahydronaphtho-oxirene (Table 1 , entry 2 ) is more reactive than styrene oxide because of the presence of strain from the additional 6-membered ring. It showed $96 \%$ conversion in ACN- $\mathrm{H}_{2} \mathrm{O}$ giving preferentially the $\alpha$-isomer along with diol (3\%). The reaction is faster in $\mathrm{ACN}-\mathrm{H}_{2} \mathrm{O}$ with $10 \%$ acetic acid $(\mathrm{AcOH})$ in the aqueous phase giving $95 \%$ conversion in around 4 min of residence time. However, the formation of diol is increased from 3 to $41 \%$, while the regioselectivity $(\alpha / \beta=12)$ is decreased. In the presence of $\mathrm{AcOH}$, the epoxide ring is protonated, resulting into a highly reactive intermediate that is prone to the attack of both azide ion and water. $\alpha$-Methylstyrene oxide (Table 1 , entry 3 ) gave $70 \%$ conversion and a regioselectivity $(\alpha / \beta)$ of 1.7 along with diol $(9 \%)$ using $\mathrm{ACN}$-water. The poor regioselectivity may be attributed to the steric hindrance caused by the methyl group at the $\alpha$-position of the styrene oxide for the attack of the azide ion. Using $\mathrm{ACN}-\mathrm{H}_{2} \mathrm{O}$ with $10 \% \mathrm{AcOH}$ in the aqueous phase enhances the conversion to $93 \%$ and affords preferentially the $\alpha$-isomer; however, diol is formed in a very high percentage $(50 \%)$. In the presence of
$\mathrm{AcOH}$, protonation of $\alpha$-methylstyrene oxide takes place, generating a considerably more positive charge on the tertiary $\alpha$-carbon atom, which is prone to the nucleophilic attack of both water and azide ion, resulting in a high percentage of diol. $\beta$-Methylstyrene oxide (Table 1 , entry 4 ) provided $41 \%$ conversion, and the $\alpha$ isomer is formed preferentially without any traces of diol formation using $\mathrm{ACN}-\mathrm{H}_{2} \mathrm{O}$. Using $\mathrm{ACN}-\mathrm{H}_{2} \mathrm{O}$ with $10 \% \mathrm{AcOH}$ in the aqueous phase, the conversions remained the same as before; however, the formation of diol (3\%) is detected.

In case of $t$-BuOAc- $\mathrm{H}_{2} \mathrm{O}$ with Tween 80 , the $\alpha$-isomer was formed preferentially in all cases (Table 1, entries $1-4$ ), and no diols were detected with GC. The lower conversions $(\leq 49 \%)$ may be ascribed to the less polar solvent medium and the absence of a homogeneous reaction mixture.

The substrate scope was extended studying different types of epoxides, viz. phenyl glycidyl ether, glycidyl methacrylate, 1-methylcyclohexene oxide, 1,2-epoxydodecane, 1,2-epoxy-9decene; the results are summarized in Table 2. Phenyl glycidyl ether (Table 2, entry 1) gave a good conversion (80\%) with predominantly $\beta$-isomer formation in $\mathrm{ACN}-\mathrm{H}_{2} \mathrm{O}$. Using $\mathrm{ACN}-$ $\mathrm{H}_{2} \mathrm{O}$ with $10 \% \mathrm{AcOH}$ in the aqueous phase, the conversion increased to $87 \%$; however, formation of diol (7\%) was detected. Glycidyl methacrylate (Table 2, entry 2) exhibited good

Table 2. Ring opening of aliphatic epoxides by $\mathrm{NaN}_{3}$ under different conditions

\begin{tabular}{|c|c|c|c|c|c|c|}
\hline Entry & Epoxide $^{a}$ & Solvent system & Conversion $(\%)$ & Azido-alcohol (\%) & Diol $(\%)$ & Regioselectivity \\
\hline \multirow{3}{*}{$1[1]$} & & $\mathrm{ACN}-\mathrm{H}_{2} \mathrm{O}^{b}$ & 80 & 80 & - & $\alpha$ Isomer traces \\
\hline & & $\mathrm{ACN}-\mathrm{H}_{2} \mathrm{O}^{d}(10 \% \mathrm{AcOH}$ in water $)$ & 87 & 80 & 7 & $\alpha$ Isomer traces \\
\hline & & $t$ - $\mathrm{BuOAc}-\mathrm{H}_{2} \mathrm{O}^{c}$ & 13 & 13 & - & $\alpha$ Isomer traces \\
\hline \multirow{3}{*}{$2[10 \mathrm{~d}]$} & & $\mathrm{ACN}-\mathrm{H}_{2} \mathrm{O}^{b}$ & 85 & 82 & 3 & $\alpha$ Isomer traces \\
\hline & & $\mathrm{ACN}-\mathrm{H}_{2} \mathrm{O}^{d}(10 \% \mathrm{AcOH}$ in water $)$ & 89 & 81 & 8 & $16(\beta / \alpha)$ \\
\hline & & $t$ - BuOAc- $-\mathrm{H}_{2} \mathrm{O}^{c}$ & 40 & 40 & - & $\alpha$ Isomer traces \\
\hline \multirow{3}{*}{$3[1]$} & & $\mathrm{ACN}-\mathrm{H}_{2} \mathrm{O}^{b}$ & 30 & 29 & $<1$ & $1.5(\beta / \alpha)$ \\
\hline & & $\mathrm{ACN}-\mathrm{H}_{2} \mathrm{O}^{d}(10 \% \mathrm{AcOH}$ in water $)$ & 78 & 62 & 16 & $2.3(\alpha / \beta)$ \\
\hline & & $t-\mathrm{BuOAc}-\mathrm{H}_{2} \mathrm{O}^{c}$ & 11 & 11 & - & $1.5(\beta / \alpha)$ \\
\hline \multirow{3}{*}{$4[27]$} & & $\mathrm{ACN}-\mathrm{H}_{2} \mathrm{O}^{b}$ & 7 & 7 & - & $13(\beta / \alpha)$ \\
\hline & & $\mathrm{ACN}-\mathrm{H}_{2} \mathrm{O}^{d}(10 \% \mathrm{AcOH}$ in water $)$ & 7 & 6.5 & $<1$ & $5(\beta / \alpha)$ \\
\hline & & $t-\mathrm{BuOAc}-\mathrm{H}_{2} \mathrm{O}^{c}$ & \multicolumn{4}{|c|}{ ND } \\
\hline \multirow[t]{2}{*}{5} & & $\mathrm{ACN}-\mathrm{H}_{2} \mathrm{O}(10 \% \mathrm{AcOH}$ in water $)$ & 14 & 13.5 & $<1$ & $5(\beta / \alpha)$ \\
\hline & & $t-\mathrm{BuOAc}-\mathrm{H}_{2} \mathrm{O}$ & \multicolumn{3}{|c|}{ Traces } & NA \\
\hline
\end{tabular}


conversions using $\mathrm{ACN}-\mathrm{H}_{2} \mathrm{O}(85 \%)$ and $\mathrm{ACN}-\mathrm{H}_{2} \mathrm{O}$ with $10 \%$ $\mathrm{AcOH}$ in the aqueous phase $(89 \%)$; however, the formation of diol increased from $3 \%$ to $8 \%$, respectively. In case of 1 -methylcyclohexene oxide (Table 2, entry 3 ), the conversion $(30 \%)$ and regioselectivity $(\beta / \alpha=1.5)$ are modest using $\mathrm{ACN}$ $\mathrm{H}_{2} \mathrm{O}$, while using $\mathrm{ACN}-\mathrm{H}_{2} \mathrm{O}$ with $10 \% \mathrm{AcOH}$ in the aqueous phase, good conversions (78\%) were achieved; however, $16 \%$ diol was formed. The regioselectivity $(\alpha / \beta=2.3)$ not only increased, but also reversed, which is due to the formation of significantly more positive charge at the tertiary $\alpha$-carbon atom upon protonation of 1-methylcyclohexene oxide, that is more susceptible to the attack of the azide ion. Both 1,2-epoxydodecane and 1,2-epoxy-9-decene showed poor conversions, $7 \%$ and $16 \%$, respectively, but with good regioselectivities $(\beta / \alpha)$ of 13 and 15 , respectively, using $\mathrm{ACN}-\mathrm{H}_{2} \mathrm{O}$. Apparently, the presences of long carbon chains make the substrates less reactive [25]. The conversions did not improve using $\mathrm{ACN}-\mathrm{H}_{2} \mathrm{O}$ with $10 \% \mathrm{AcOH}$ in the aqueous phase, and the regioselectivity decreased compared to $\mathrm{ACN}-\mathrm{H}_{2} \mathrm{O}$, which is ascribed to the fact that, upon protonation of the substrates (Table 2, entries 4 and 5), the azide ion prefers to attack the $\alpha$-carbon.

Using $t$ - BuOAc- $\mathrm{H}_{2} \mathrm{O}$ with Tween80, the conversions are not impressive $(\leq 13 \%)$ for all epoxides in Table 2, except for glycidyl methacrylate (Table 2 , entry 2 ) showing $40 \%$ conversion. The $\beta$-isomers are formed preferentially for all substrates, and no diol formation is detected.

The reactivity of aliphatic epoxides is poor under the optimized reaction conditions used above. To increase the conversions, different Lewis acids $\left(\mathrm{LiBF}_{4}, \mathrm{GaCl}_{3}, \mathrm{BF}_{3} \cdot \mathrm{Et}_{2} \mathrm{O}\right.$, and $\mathrm{CeCl}_{3} \cdot 7 \mathrm{H}_{2} \mathrm{O}$ ) were explored in case of 1 -methylcyclohexene oxide, but they either precipitated while preparing the samples or clogged the channels while running the microreactor. By varying the solvent to toluene-water, isopropyl alcohol-water, dioxane-water, DMSO-water, and DMF-water and increasing the temperature from 75 to $90{ }^{\circ} \mathrm{C}$, it turned out that $\mathrm{DMF}$-water and DMSO-water gave excellent conversions, while the regioselectivity $(\beta / \alpha)$ was around 2 (Table 3 ).

\section{Conclusions}

In conclusion, we have shown that, in general, the regioselectivity of the ring opening of epoxides becomes higher by changing the solvent from $\mathrm{ACN}-\mathrm{H}_{2} \mathrm{O}$ to $t$ - $\mathrm{BuOAc}-\mathrm{H}_{2} \mathrm{O}$ containing Tween 80 although, in the latter case, the conversions are lower. The presence of a surfactant stabilizes the interface in the biphasic system. To our best knowledge, the latter conditions involve the first example of azidolysis under biphasic circumstances. Addition of $10 \% \mathrm{AcOH}$ to the aqueous phase of ACN- $\mathrm{H}_{2} \mathrm{O}$ accelerates the reaction and enhances the attack of the azide group at the carbon atom bearing more substituents although, in most cases, accompanied with diol formation. In the case of the ring opening of 1-methylcyclohexene oxide, the regioselectivity is even reversed from $(\beta / \alpha=1.5)$ to $(\alpha / \beta=2.3)$.

Compared to lab scale, in general, there is a slight improvement in the conversion of the ring opening of epoxides in a microreactor with pillars, while the regioselectivity remains the same. This study clearly demonstrated that a microreactor with pillars is a very useful vehicle to study not only biphasic reactions but also homogeneous reactions due to their intrinsically effective mixing.

\section{Experimental section}

4.1. Materials. The chemicals and solvents were purchased from Sigma Aldrich unless otherwise stated and were used without purification unless specified. Styrene oxide (97\%) was purified by vacuum distillation, $\mathrm{NaN}_{3}$ (BioXtra), $\mathrm{NH}_{4} \mathrm{Cl}(99+\%$, Acros organics), $t$-butyl acetate $(>99 \%)$, Tween ${ }^{\circledR} 80$ (pure, Acros organics), acetic acid (>99\%), and 1-methylcyclohexene oxide ( $>95 \%$, TCI Europe); $\alpha$-methylstyrene oxide (95\%, ABCR chemicals) was purified by vacuum distillation, 1,2dihydronaphthalene (98\%), phenyl glycidyl ether (99\%), glycidyl methacrylate (>97\%), 1,2-epoxy-9-decene (96\%), trans-1-phenyl1-propene (>98\%), 2-methyl-1-phenyl-1-propene (99\%), $\mathrm{LiBF}_{4}$ (98\%), $\mathrm{BF}_{3} \mathrm{OEt}_{2}(36 \%), \mathrm{GaCl}_{3}$ (99.99\% trace metals basis), and $\mathrm{CeCl}_{3} \cdot 7 \mathrm{H}_{2} \mathrm{O}(99.9 \%$ trace metals basis); and water was purified with the Milli-Q pulse (Millipore, $R=18.2 \mathrm{M} \Omega \mathrm{cm}$ ) ultra pure water system and acetonitrile (for analysis EMSURE ${ }^{\circledR}$ ACS, Reag. Ph Eur, Merck). Tetrahydronaphthalene-1,2-epoxide [22] and $\beta$-methylstyrene oxide [28] were synthesized according to literature procedures.

4.2. Methods. Analytical TLC was performed using Merckprepared plates (silica gel 60 F-254 on aluminium). Column chromatography was carried out on Merck silica gel 60 (230400 mesh). ${ }^{1} \mathrm{H}$ NMR and ${ }^{13} \mathrm{C}$ NMR spectra were recorded on a Varian Unity INOVA (300 MHz) spectrometer. ${ }^{1} \mathrm{H}$ NMR chemical shift values $(300 \mathrm{MHz})$ are reported as $\delta$ using the residual solvent signal as an internal standard $\left(\mathrm{CDCl}_{3}, \delta 7.257\right) .{ }^{13} \mathrm{C}$ NMR chemical shift values $(75 \mathrm{MHz})$ are reported as $\delta$ using the residual solvent signal as an internal standard $\left(\mathrm{CDCl}_{3}, \delta\right.$ 77.0). All NMR spectra were recorded in $\mathrm{CDCl}_{3}$. The electrospray ionization (positive mode) high-resolution mass spectrum was recorded on a WATERS LCT mass spectrometer. Gas chromatography (GC) samples were prepared by collecting a $40-\mu \mathrm{L}$ reaction mixture sample $(20 \mu \mathrm{L}$ organic and $20 \mu \mathrm{L}$ aqueous), which was diluted to $80 \mu \mathrm{L}$ in a glass insert, with $\mathrm{ACN}$ for $\mathrm{ACN}$-water and with $t$-BuOAc for $t$-BuOAc-water containing Tween80. One microliter samples of the organic layer of the reaction mixtures were injected onto an Agilent DB-5MS UI column $(30 \mathrm{~m} \times 0.32 \mathrm{~mm}$ i.d., $25 \mu \mathrm{m}$ film thickness) with a constant pressure of $11.9 \mathrm{psi}$. The oven temperature was held at $65{ }^{\circ} \mathrm{C}$ for $1 \mathrm{~min}$ and increased linearly at a rate of $10{ }^{\circ} \mathrm{C} / \mathrm{min}$ to $250{ }^{\circ} \mathrm{C}$ with a final hold of $5 \mathrm{~min}$. GC conversions were determined from the area under the curve of the peaks corresponding to epoxide and products. The peaks were identified by injecting the products, which were separately synthesized by lab scale experiments following literature procedures. The error bars in Figures 1 and 3 represent the standard deviation calculated over two measurements for each point. Fluorescence microscopy images were taken using an Olympus inverted research microscope IX71 equipped with a mercury burner U-RFL-T as light source and a digital Olympus DR70 camera for image acquisition. Violet excitation

Table 3. Ring opening of 1-methylcyclohexene oxide by $\mathrm{NaN}_{3}$ in different solvent mixtures

\begin{tabular}{lcccc}
\hline Reaction conditions ${ }^{a}$ & Temperature $\left({ }^{\circ} \mathrm{C}\right)$ & Conversion $(\%)$ & Yield $(\%)$ & Diol $(\%)$ \\
\hline Toluene-water & 90 & 16.5 & 16 & \multicolumn{1}{c}{ Regioselectivity $(\beta / \alpha)$} \\
Isopropyl alcohol-water & 80 & 55 & 53 & 1.2 \\
Dioxane-water & 85 & 57 & 55 & 1.7 \\
DMF-water & 90 & 96 & 93 & 1.6 \\
DMSO-water & 90 & 97 & 93.5 & 3 \\
\end{tabular}

${ }^{a}$ Reaction conditions: Syringe 1: $\mathrm{NaN}_{3}(1.25 \mathrm{M})$ and $\mathrm{NH}_{4} \mathrm{Cl}(0.55 \mathrm{M})$ in $\mathrm{H}_{2} \mathrm{O}$. Syringe 2: 1-methylcyclohexene oxide $(0.5 \mathrm{M})$ in the respective solvent. Reactions were carried out in a microreactor with pillars. Residence time: 29 min. Flow rates of aqueous and organic phases are equal. 
$\left(\lambda_{\mathrm{ex}}=315-380 \mathrm{~nm}\right)$ and blue emission $\left(\lambda_{\mathrm{em}}=430-490 \mathrm{~nm}\right)$ was filtered using the U-MWB5 Olympus filter. The fluorescence microscopy images were acquired at $75{ }^{\circ} \mathrm{C}$.

4.3. 1-Azido-2-Hydroxy-9-Decene. To a solution of 1,2epoxy-9-decene $(771 \mathrm{mg}, 5 \mathrm{mmol})$ in a mixture of $\mathrm{MeOH}$ $(8 \mathrm{~mL})$ and $\mathrm{H}_{2} \mathrm{O}(1 \mathrm{~mL}), \mathrm{NH}_{4} \mathrm{Cl}(588 \mathrm{mg}, 11 \mathrm{mmol})$ and $\mathrm{NaN}_{3}$ (1.625 g, $\left.25 \mathrm{mmol}\right)$ were added. The resulting reaction mixture was heated at reflux overnight. The solution was cooled to room temperature, and the product was extracted with dichloromethane $(3 \times 50 \mathrm{~mL})$ and washed with brine $(2 \times 75 \mathrm{~mL})$. The combined organic layers were dried with $\mathrm{Na}_{2} \mathrm{SO}_{4}$, filtered, and concentrated under reduced pressure. The resulting crude product was purified by column chromatography using 7:3 ethyl acetate/hexane as eluent to afford the target compound as a colorless oil (91 \%). ${ }^{1} \mathrm{H}$ NMR: $\delta 5.72-5.86(\mathrm{~m}, 1 \mathrm{H},=\mathrm{CH}), 5.01-4.91$ (m, $2 \mathrm{H},=\mathrm{CH}_{2}$ ), 3.73 (br s, $1 \mathrm{H}, \mathrm{CHOH}$ ), 3.35 (dd, $1 \mathrm{H}, J=3$ and $\left.12 \mathrm{~Hz}, \mathrm{CHHN}_{3}\right), 3.23\left(\mathrm{dd}, 1 \mathrm{H}, J=6\right.$ and $12 \mathrm{~Hz}, \mathrm{CH} H \mathrm{~N}_{3}$ ), 2.0-2.06 (m, $\left.2 \mathrm{H}, \mathrm{CH}_{2}\right), 1.32-1.46\left(\mathrm{~m}, 10 \mathrm{H}, \mathrm{CH}_{2}\right.$ and $\left.\mathrm{CH}_{3}\right) ;{ }^{13} \mathrm{C}$ NMR: $\delta$ 139.3, 114.4, 71.1, 57.3, 34.5, 33.9, 29.6, 29.2, 29.1, 25.6; HRMS (ESI): $m / z$ 198.1355 $[\mathrm{M}+\mathrm{H}]^{+}$, calculated for $\mathrm{C}_{10} \mathrm{H}_{19} \mathrm{~N}_{3} \mathrm{O}: 198.1528$.

4.4. Flow Apparatus. In all microreactor experiments, the sample solutions were mobilized by means of a PHD 22/2000 series syringe pump (Harvard Apparatus, United Kingdom) equipped with $250-\mu \mathrm{L}$ flat tip syringes (Hamilton). Syringes were connected to fused silica capillaries $(100 \mu \mathrm{m}$ i.d., $362 \mu \mathrm{m}$ o.d., Polymicro Technologies) by means of Upchurch Nanoport ${ }^{\mathrm{TM}}$ assembly parts (i.e., Nano-Tight ${ }^{\mathrm{TM}}$ unions and fittings, Upchurch Scientific Inc. USA). During the experiments, the microreactor was placed in a home-built chip holder designed for fitting fused silica fibers into the inlet/outlet chip reservoirs by means of commercially available Upchurch Nanoport ${ }^{\mathrm{TM}}$ assembly parts. The temperature in the microreactor was controlled by interfacing a thermoelectric module with a heat sink to the microreactor. The temperature variation on the glass surface of the microreactor measured with a thermocouple was $< \pm 0.1{ }^{\circ} \mathrm{C}$. A glass microreactor with pillars inside the microfluidic channels with a residual volume of $7.25 \mu \mathrm{L}$ was purchased from Micronit Microfluidics. It has dimensions of $645.6-\mathrm{mm}$ length, $52-\mu \mathrm{m}$ depth, 254- $\mu \mathrm{m}$ channel top width, and $150-\mu \mathrm{m}$ channel bottom width. A glass microreactor without pillars with the same dimensions has a residual volume of $7.85 \mu \mathrm{L}$.

4.5. Microreactor Experiments. Two $250-\mu \mathrm{L}$ syringes, one with the aqueous solution and the other with the organic solution containing a substrate (for concentrations of the reagents, see the notes under Figures 1, 3 and Tables 1-3), were loaded onto the syringe pump and connected to the fused silica capillaries through a Nanoport assembly (using peek needle port, nanotight union, capillary tubing, nanotight nut and ferrule). The ends of the capillaries were connected to the inlets of a microreactor with or without pillars through a Nanoport assembly (using nut, steel compression ring, and ferrule). The outlet of the microreactor was again connected to the capillaries through a Nanoport assembly (using nut, steel compression ring, capillary tubing, and ferrule) and directed to a glass vial, where the reaction product was collected and analyzed offline using GC. The flow rates were varied from $1,0.5,0.25$, to 0.125 $\mu \mathrm{L} / \mathrm{min}$, which resulted in residence times of $3.625,7.25,14.5$, and $29 \mathrm{~min}$, respectively, using a microreactor with pillars. In order to obtain the same residence times using a microreactor without pillars, the flow rates were increased to $1.08,0.54,0.27$, and $0.135 \mu \mathrm{L} / \mathrm{min}$, respectively.

Acknowledgments. We acknowledge the financial support from the Netherlands Organization for Scientific Research and Advanced Chemical Technologies for Sustainability (NWOACTS) through the Process-on-a-Chip (POAC) program. We are very grateful for the technical assistance of R. J. M. Egberink.

\section{Supporting information}

Figures of the azidolysis of styrene oxide in $t-\mathrm{BuOAc}-\mathrm{H}_{2} \mathrm{O}$ using different Tween 80 concentrations, under comparable microreactor and lab scale conditions, and in $1: 1 \quad \mathrm{ACN}-\mathrm{H}_{2} \mathrm{O}$ at different temperatures.

\section{References}

1. Chini, M.; Crotti, P.; Macchia, F. Tetrahedron Lett. 1990, 31, 5641-5644

2. Jurczak, J. In Preparative Carbohydrate Chemistry; Hanessian, S.; Ed.; Marcel Dekker: New York, 1997; pp 595-614.

3. Coe, D. M.; Myers, P. L.; Parry, D. M.; Roberts, S. M.; Storerb, R. J. Chem. Soc., Chem. Commun. 1990, 151-153.

4. Smith, B. T.; Gracias, V.; Aubé, J. J. Org. Chem. 2000, 65, 3771-3774.

5. Badiang, J. G.; Aubé, J. J. Org. Chem. 1996, 61, 2484-2487.

6. Tae Cho, B.; Kyu Kang, S.; Hye Shin, S. Tetrahedron: Asymmetry 2002, 13, 1209-1217.

7. Scriven, E. F. V; Turnbull, K. Chem. Rev. 1988, 88, 297-368.

8. (a) Behrens, C. H.; Sharpless, K. B. J. Org. Chem. 1985, 50, 5696-5704; (b) Crotti, P.; Di Bussolo, V.; Favero, L.; Macchia, F.; Pineschi, M. Tetrahedron Lett. 1996, 37, 1675-1678; (c) Kazemi, F.; Kiasat, A. R.; Ebrahimi, S. Synth. Commun. 2003, 33, 999-1004; (d) Fringuelli, F.; Pizzo, F.; Vaccaro, L. J. Org. Chem. 2001, 66, 4719-4722.

9. Fringuelli, F.; Piermatti, O.; Pizzo, F.; Vaccaro, L. J. Org. Chem. 1999, 64, 6094-6096.

10. (a) Schneider, C. Synlett 2000, 1840-1842; (b) Kiasat, A. R.; Mirzajani, R.; Shalbaf, H.; Tabatabaei, T.; Fallah-Mehrjardi, M. J. Chin. Chem. Soc. 2009, 56, 594-599; (c) Kiasat, A. R.; Badri, R.; Zargar, B.; Sayyahi, S. J. Org. Chem. 2008, 73, 8382-8385; (d) Tamami, B.; Mahdavi, H. Tetrahedron Lett. 2001, 42, $8721-8724$.

11. Sabitha, G.; Babu, R. S.; Rajkumar, M.; Yadav, J. S. Org. Lett. 2002, 4, 343-345; (b) Bhaumik, K.; Mali, U. W.; Akamanchi, K. G. Synth. Commun. 2003, 33, 1603-1610.

12. Parker, R. E.; Isaacs, N. S. Chem. Rev. 1959, 59, 737-799; (b) Smith, J. G. Synthesis 1984, 629-656; (c) Pocker, Y.; Ronald, B. P.; Anderson, K. W. J. Am. Chem. Soc. 1988, 110, 6492-6497; (d) Bonollo, S.; Lanari, D.; Vaccaro, L. Eur. J. Org. Chem. 2011, 2587-2598.

13. Microreactors in Organic Synthesis and Catalysis; Wirth, T., Ed.; WileyVCH: Weinheim, 2008.

14. (a) Watts, P.; Wiles, C. Chem. Commun. 2007, 443-467; (b) Fukuyama, T.; Rahman, T.; Sato, M.; Ryu, I. Synlett 2008, 2008, 151-163; (c) Hartman, R.

L.; McMullen, J. P.; Jensen, K. F. Angew. Chem. Int. Ed. 2011, 50, 7502-7519;

(d) Brivio, M.; Verboom, W.; Reinhoudt, D. N. Lab Chip 2006, 6, 329-344.

15. Kobayashi, J., Mori, Y.; Kobayashi, S. Chem. Asian J. 2006, 1, 22-35.

16. Kiwi-Minsker, L.; Renken, A. Catal. Today 2005, 110, 2-14.

17. Jähnisch, K.; Hessel, V.; Löwe, H.; Baerns, M. Angew. Chem. Int. Ed. 2004, 43, 406-446.

18. Caron, M.; Sharpless, K. B. J. Org. Chem. 1985, 50, 1557-1560.

19. Amantini, D.; Fringuelli, F.; Piermatti, O.; Tortoioli, S.; Vaccaro, L. ARKIVOC 2002, xi, 293-311.

20 . Using these very small microreactors $(7.25 \mu \mathrm{L})$, the throughput is $23 \mathrm{mg} /$ day product formation for a residence time of $14 \mathrm{~min}$ and $30 \mathrm{~s}$.

21. Ahmed, B.; Barrow, D.; Wirth, T. Adv. Synth. Catal. 2006, 348, 1043-1048.

22. Sowmiya, M.; Tiwari, A. K.; Saha, S. K. J. Colloid Interface Sci. 2010 , $344,97-104$.

23. Using these very small microreactors $(7.25 \mu \mathrm{L})$, the throughput is $12 \mathrm{mg}$ /day product formation for a residence time of $14 \mathrm{~min}$ and $30 \mathrm{~s}$.

24. Li, R.; Jansen, D. J.; Datta, A. Org. Biomol. Chem. 2009, 7, 1921-1930.

25. Molinaro, C.; Guilbault, A.-A.; Kosjek, B. Org. Lett. 2010, 12, 3772-3775.

26. Saito, K.; Okawara, M.; Harada, K. React. Polym. 1991, 15, 79-83.

27. Stewart, I. C.; Lee, C. C.; Bergman, R. G.; Toste, F. D. J. Am. Chem. Soc. 2005, 127, 17616-17617.

28. Page, P. C. B.; Parker, P.; Buckley, B. R.; Rassias, G. A.; Bethell, D. Tetrahedron 2009, 65, 2910-2915. 